ORIGINAL ARTICLE

\title{
Differential effects of lead exposure on components of verbal memory
}

\author{
M L Bleecker, D P Ford, K N Lindgren, V M Hoese, K S Walsh, C G Vaughan
}

Occup Environ Med 2005;62:181-187. doi: 10.1136/oem.2003.011346

See end of article for authors' affiliations .....................

Correspondence to: DrM L Bleecker, Center for Occupational and Environmental Neurology, 3901 Greenspring Ave., Suite 101, Baltimore, MD 21211, USA; coen@msn. com

Accepted 1 December 2004

\begin{abstract}
Aims: To determine if verbal learning and memory requiring acquisition and retention of information is differentially affected by lead exposure.

Methods: The Rey Auditory Verbal Learning Test (RAVLT), a test of verbal learning and memory, was administered to 256 English speaking lead smelter workers who had a mean (SD) age of 41 (9.4) years and employment duration of 17 (8.1) years. Lead exposure variables, based on up to 25 years of prior blood lead data, included a mean (SD) current blood lead (PbB) of 28 (8.8) $\mu \mathrm{g} / \mathrm{dl}$, working lifetime time weighted average blood lead (TWA) of 39 (12.3) $\mu \mathrm{g} / \mathrm{dl}$, and working lifetime integrated blood lead index (IBL) of 728 (434.4) $\mu \mathrm{g}-\mathrm{y} / \mathrm{dl}$. Associations of these chronic and recent lead exposure variables with measures from the RAVLT were modelled through multiple linear regressions after controlling for age and educational achievement.

Results: PbB was not associated with any of the RAVLT variables. However, TWA and IBL contributed significantly to the explanation of variance of measures of encoding/storage and retrieval but not to immediate memory span, attention, and learning. Grouping study participants by RAVLT performance according to three recognised clinical memory paradigms showed significantly higher TWA and IBL in the group with "generalised memory impairment" after adjusting for age and educational achievement. We examined recall mechanisms in each group by serial position in the word list and found stronger primacy (recall of words from the beginning of the list) in the "no impairment" and "retrieval difficulties" groups while the "generalised memory impairment" group had better performance on recency (recall of words from the end of the list).

Conclusions: Lead exposure over years and not $\mathrm{PbB}$ interfered with the organisation and recall of previously learned verbal material. Chronic lead exposure affects encoding/storage and retrieval of verbal information.
\end{abstract}

mpairment of visuomotor function is the neuropsychological alteration most frequently associated with occupational inorganic lead exposure. ${ }^{1-11}$ Verbal memory, also affected by inorganic lead exposure, is more difficult to measure. ${ }^{2-8} 1^{12-15}$ The original World Health Organisation Neurobehavioural Core Test Battery-designed to evaluate the neurotoxic effects of chemical exposure worldwideomitted a test of verbal memory because of problems with cultural bias and difficulties validating across languages. ${ }^{16}{ }^{17}$ The World Health Organisation has since corrected this omission by creating tests of verbal memory-word listswith low intercultural variability. ${ }^{18}$

Many published studies have related inorganic lead exposure to different measures of verbal memory. Several have found associations between inorganic lead exposure and digit span, ${ }^{7} 10^{12} 14$ a measure of immediate verbal recall and auditory attention. ${ }^{19}$ Additionally, Stollery and colleagues ${ }^{5}$ reported weak evidence of impairment in delayed recall of a word list when blood lead $(\mathrm{PbB})$ was greater than $40 \mu \mathrm{g} / \mathrm{dl}$. Poorer performance on a paired associate verbal learning test also occurred in individuals having a $\mathrm{PbB}$ greater than $60 \mu \mathrm{g} /$ $\mathrm{dl}^{2}{ }^{2}$ Yet another study found a dose-effect relation between working-lifetime cumulative lead exposure and logical memory, a task measuring the immediate recall of a short story. ${ }^{7}$

The Rey Auditory Verbal Learning Test (RAVLT) is a word list test that measures verbal learning and memory whose subscores reflect different verbal memory processes. RAVLT performance patterns differ in a variety of disorders including impaired memory associated with neuropsychiatric conditions such as Alzheimer's dementia, closed head trauma, attention deficit disorder, psychiatric disorders, alcoholism, and amnesia. ${ }^{20-23}$ In fact the RAVLT was superior in identifying group membership (control versus memory impaired) when compared to other neuropsychological tests. $^{24}$ While some scores on the RAVLT have correlated with measures of inorganic lead exposure, ${ }^{7813}$ the limited presentation of the various subscores in past publications preclude any determination of the verbal memory processes most sensitive to inorganic lead exposure.

Verbal learning and memory consists of a number of distinct processes each having a different neuroanatomical substrate and, consequently, different potential neurotoxicological targets. The most fundamental of these processes is the acquisition and retention of information. ${ }^{25-27}$ Acquisition in turn may be divided into memory span and learning increment over repeated trials, ${ }^{19}$ while retention-reflecting the maintenance and accessibility of learned information over various intervals of time-consists of storage and retrieval. ${ }^{25} 28$

Word list tests, such as the RAVLT, provide means of assessing each of these components of verbal learning and memory. In addition to the number of words recalled after various trials, the way in which learned information is recalled can give even further insight into specific memory mechanisms. Differential serial position performance reflects the role of primacy and recency in learning. Better recollection of words from the beginning of the list (primacy) reflects

Abbreviations: IBL, integrated blood lead; PbB, blood lead; RAVLT, Rey Auditory Verbal Learning Test; TWA, time weighted average; WRAT, Wide Range Achievement Test-Revised 
stronger, more active learning while recollection of words from the end of the list (recency) reveals more passive learning. ${ }^{29}$ Alternatively some authors have suggested that words from the end of the list are stored in short term memory, while those from the beginning have already moved into long term memory. ${ }^{30}$ Patients with early Alzheimer-type dementia used a recency pattern of learning suggesting encoding difficulties, while those with Parkinson's dementia showed a primacy and recency pattern similar to that of controls. ${ }^{23}{ }^{31}$ Patients with acquired immunodeficiency syndrome (AIDS) had both intact primacy and recency but recalled significantly fewer words from the middle of the word list, suggesting intact encoding but impaired recall efficiency. ${ }^{27}$ To date there has been no evaluation of serial position effect in lead exposed workers.

In this study we address the following two hypotheses: (1) lead exposure differentially affects components of verbal memory; and (2) lead exposure is associated with impaired verbal memory using clinical criteria that reflect specific weaknesses in the components of verbal memory.

\section{METHODS \\ Subjects}

We drew subjects from a population of workers at a Canadian primary lead smelter who had previously agreed to participate in a larger study of the neurobehavioural effects of chronic inorganic lead exposure. ${ }^{7}$ The subsample chosen for this particular arm of the study consisted of all participants who identified their preferred language as English and who had no history of significant neurological or psychiatric conditions. Data on potential confounders such as education, alcohol intake, and current smoking were collected (see table 1). All workers volunteered for the study and signed an informed consent approved by a combined provincialmanagement-labor oversight committee.

\section{Exposure}

As employees of a primary smelter, participants were routinely exposed to several sources of inorganic lead dust, and to a lesser extent, lead fumes. Since the time the smelter began operations in 1966 all employees routinely had their $\mathrm{PbB}$ tested at least several times a year. The frequency of $\mathrm{PbB}$ measurements depended on the relative degree of lead exposure for any given job and whether the employee had been relocated because of lead overexposure. PbB levels mandating relocation dropped from $90 \mu \mathrm{g} / \mathrm{dl}$ in 1966 to $75 \mu \mathrm{g} / \mathrm{dl}$ in 1974, $65 \mu \mathrm{g} / \mathrm{dl}$ in 1987, and $50 \mu \mathrm{g} / \mathrm{dl}$ in 1990 .

In general the smelter workers in this study had chronic inorganic lead exposure that had been high in the distant past but lower in the more proximate past with relatively low $\mathrm{PbB}$ values at the time of this study.

Table 1 Demographic information for 254 current smelter workers

\begin{tabular}{lrrl}
\hline Variable & Mean & \multicolumn{1}{l}{ SD } & Range \\
\hline Age (years) & 40.8 & 9.41 & $20-63$ \\
Education (years) & 10.6 & 2.95 & $0-18$ \\
WRAT-R* & 50.7 & 15.00 & $13-84$ \\
No. cigarettes $†$ & 2.4 & 6.10 & $0-25$ \\
Alcohol use & 6.7 & 7.12 & $0-28$ \\
Years employed & 17.1 & 8.08 & $0.20-26$ \\
Blood lead ( $\mu \mathrm{g} / \mathrm{dl})$ & 27.7 & 8.79 & $4-62$ \\
TWA $(\mu \mathrm{g} / \mathrm{dl})$ & 39.0 & 12.32 & $4-66$ \\
IBL $(\mu \mathrm{g}-\mathrm{y} / \mathrm{dl})$ & 728.2 & 434.36 & $0.6-1625.7$ \\
\hline
\end{tabular}

*Wide Range Achievement Test-Reading.

†Number of cigarettes smoked per day.

$\ddagger 1$ unit $=12$ oz beer, 6 oz wine, 1 oz hard liquor per week.
Blood samples were collected pre-shift by facility nursing staff in the infirmary, a building physically distinct from the smelter, using standard techniques to minimise the likelihood of lead contamination of the samples. Sample analysis initially was performed by a local off-site laboratory using the dithizone method. By the early 1970s these analyses were conducted by a regional contract laboratory using graphite furnace atomic absorption spectrophotometry; this laboratory subsequently became a participant in the interlaboratory blood lead proficiency testing programme of the then United States Centers for Disease Control. For the purposes of this study $\mathrm{PbB}$ results from the two different laboratories were considered equivalent.

Lead dose metrics (see table 1) calculated for each study participant included: (1) PbB ( $\mu \mathrm{g} / \mathrm{dl})$ - a measure of current blood lead, specifically, the blood lead at the time of verbal memory testing; (2) integrated blood lead (IBL) ( $\mu$ g-y/dl) -a measure of cumulative lead dose integrated over the working lifetime; and (3) time weighted average (TWA) ( $\mu \mathrm{g} / \mathrm{dl})-\mathrm{a}$ measure of average lead dose over the period of employment: the working lifetime weighted average blood lead. Methods for calculating the latter two have been described previously. ${ }^{32}$

\section{Test of verbal memory}

The RAVLT consists of five presentations of a 15 word list. Each presentation is followed by free recall of the word list with scoring based on the number of correct responses. Errors are noted as repetitions (a word from the list recalled more than once), intrusions (a word previously presented in another subtest of the neuropsychological battery), or confabulations (a word not previously presented in the neuropsychological battery). Delayed recall of the word list is assessed after 30 minutes, followed by a recognition trial of identifying the 15 test words from a list of 50 words that include distracters-words phonemically and semantically similar to the original words. ${ }^{19}$ Different subscores from the RAVLT correspond to different memory processes: trial I measures immediate memory span and attention; trial $\mathrm{V}$ is a measure of best learning (in most cases this represents the maximum number of words recalled on a trial); total score represents the incremental learning of words across the five trials; delayed recall assesses storage and retrieval; and recognition measures storage of verbal material.

In addition to analysing raw score data we used the combination of scores from trial V (best learning) and recognition (storage) to identify three verbal memory groups: group I had normal memory performance on trial $\mathrm{V}(\geqslant 11)$ and recognition $(\geqslant 12)$; group II had impaired retrieval on trial $\mathrm{V}(<11)$ but normal recognition $(\geqslant 12)$, suggesting that information was in storage but could not be retrieved for free recall; and group III had impaired performance on trial V $(<11)$ and recognition $(<12)$ compatible with a generalised memory impairment. ${ }^{19}$ These cut-off scores used to define the three memory groups were derived by taking an age appropriate mean minus one standard deviation as reported in a large normative study of healthy men. ${ }^{33}$ To investigate memory strategies by these three groups we compared serial position effect for the words recalled to assess the impact of primacy (recollection of words from the beginning of the list) versus recency (recollection of words from the end of the list) on a supraspan list. ${ }^{30}$

\section{Educational achievement}

A measure of educational achievement tends to be more robust than years of education as a surrogate for education, particularly in working populations such as ours. ${ }^{34}$ The Wide Range Achievement Test-Revised reading score (WRAT) requires the oral pronunciation of 75 words out of context. 
Table 2 RAVLT scores stratified by age

\begin{tabular}{|c|c|c|c|c|c|}
\hline \multirow[b]{2}{*}{ RAVLT variables } & \multirow[b]{2}{*}{$\begin{array}{l}\text { Full group } \\
(\mathrm{n}=254)\end{array}$} & \multicolumn{4}{|l|}{ Age (years) } \\
\hline & & $\begin{array}{l}20-34 \\
(n=63)\end{array}$ & $\begin{array}{l}35-41 \\
(n=61)\end{array}$ & $\begin{array}{l}42-47 \\
(n=69)\end{array}$ & $\begin{array}{l}48-63 \\
(n=61)\end{array}$ \\
\hline Trial I & $5.7 \pm 1.81(1-12)^{*}$ & $6.4 \pm 2.00(2-12)$ & $5.9 \pm 1.68(3-9)$ & $5.6 \pm 1.69(2-10)$ & $4.8 \pm 1.45(1-9)$ \\
\hline Trial V & $10.8 \pm 2.49(4-15)$ & $12.2 \pm 1.89(7-15)$ & $10.7 \pm 2.35(5-15)$ & $10.4 \pm 2.46(5-15)$ & $9.5 \pm 2.36(4-15)$ \\
\hline Total score & $43.9 \pm 9.94(15-72)$ & $49.8 \pm 8.30(35-72)$ & $43.7 \pm 8.78(23-62)$ & $42.6 \pm 9.31(20-63)$ & $37.7 \pm 9.12(15-62)$ \\
\hline Delayed recall & $8.3 \pm 3.33(0-15)$ & $10.4 \pm 2.55(5-15)$ & $8.1 \pm 2.94(2-15)$ & $7.8 \pm 3.34(0-15)$ & $6.8 \pm 3.50(0-15)$ \\
\hline Recognition & $12.5 \pm 2.31(4-15)$ & $13.6 \pm 1.52(10-15)$ & $12.4 \pm 2.08(7-15)$ & $12.2 \pm 2.64(4-15)$ & $11.7 \pm 2.71(5-15)$ \\
\hline
\end{tabular}

In order to decode the word neither comprehension nor knowledge of the meaning of the word is needed. Ten consecutive errors end the test. WRAT raw scores measure educational achievement ${ }^{35}$ that converts to an estimated reading grade level and is a marker of premorbid intelligence. $^{34}$

\section{Statistical analysis}

We analysed the data using primarily SPSS-PC, version 11.5 supplemented by Stata 8 for some of the regression diagnostics. Initial exploration using univariate statistics and graphics was done to check for outliers and other gross violations of model assumptions. We then reviewed scatter plots of the RAVLT outcome variables versus the exposure variables and covariates for suggestions of linear relations and for manifest violations of the assumptions underlying multiple linear regression (for example, nonlinearity, heteroscedasticity), the primary tool of our analysis. Zero order correlations confirmed the well recognised effect of age and measures of intelligence (WRAT) on RAVLT performance that has been previously reported in both our studies and in the literature. $^{781336}$ Because of the absence of any statistically significant relation between smoking or alcohol variables with the RAVLT variables, partial correlations were conducted only controlling for age and WRAT.

We initially regressed RAVLT variables on the two covariates, age and WRAT and used regression diagnostics such as partial residual plots and if indicated, a least squares curve fitting procedure. This procedure revealed nonlinearity in the relation between age and the delayed recall variable that was addressed by stratifying age into four groups-ages 20 to $34(n=63)$, ages 35 to $41(n=61)$, ages 42 to 47 $(n=69)$, and ages 48 to $63(n=61)$. Dummy variables were used in the model as categorical variables rather than as a continuous one. This was only done for models having delayed recall as the outcome; in all others we kept age continuous.

In the full regression analyses we modelled the effect of the exposure variables on the RAVLT variables after first entering age and WRAT in order to examine what, if any, explanatory power exposure had after controlling for these two covariates.
Regression diagnostics of these models failed to detect significant violations of model assumptions.

We then related membership in the three memory groups we had created to lead exposure by modelling each of the three lead dose variables using ANCOVA while controlling for age and WRAT. Finally, we analysed the types of recollection errors using ANOVA and looked for evidence of serial position effect from the beginning, middle, and end of the word list using ANCOVA. An alpha of 0.05 was used for the correlations and when testing both hypotheses. A Bonferroni method was employed when performing multiple post hoc comparisons. This resulted in using a more stringent alpha (0.01) to limit the chance of making a type I error.

\section{RESULTS}

Information on the lead dose metrics and covariates is summarised in table 1 . Review of medication usage and medical conditions, including depressive symptoms, failed to show any relation with the outcome variables or lead dose metrics.

Table 2 stratifies the RAVLT variables by age showing the diminished RAVLT performance with increasing age. All four age groups from youngest to oldest showed similar incremental learning patterns from trial I to trial V. Using the calculation (trial V - trial I)/trial I with the mean scores for each age group the increases in learning were $90 \%, 80 \%, 88 \%$, and $101 \%$. As presented in table 3, all RAVLT scores when stratified by WRAT reading grade level $(\leqslant 6$ grade, $7-11$ grade, and $\geqslant 12$ grade) showed better performance in the higher grades compared with the lower grades. As with age, the reading groups showed comparable incremental learning from trial I to trial $\mathrm{V}$ (grade $\leqslant 6=85 \%$, grade $7-11=95 \%$, and grade $\geqslant 12=83 \%$ ).

In table 4 we present the bivariate correlation matrix for the five outcome, three exposure, and two confounding variables-age and WRAT. In table 5, the partial correlation matrix of the outcome and lead dose variables adjusting for the confounders age and WRAT failed to show a significant relation between $\mathrm{PbB}$ and any of the RAVLT variables. TWA on the other hand correlated significantly with trial $\mathrm{V}(r=-0.14, \mathrm{p}<0.05)$ and delayed recall $(r=-0.14, \mathrm{p}<0.05)$. Likewise IBL correlated significantly

Table 3 RAVLT variables stratified by educational achievement

\begin{tabular}{llll}
\hline \multicolumn{5}{l}{ WRAT-R reading grade level } \\
\cline { 2 - 4 } RAVLT variables & $\begin{array}{l}\leqslant 6 \\
(\mathbf{n}=\mathbf{8})\end{array}$ & $\begin{array}{l}7-11 \\
(\mathbf{n}=110)\end{array}$ & $\begin{array}{l}\geqslant 12 \\
(\mathbf{n}=57)\end{array}$ \\
\hline Trial I & $5.2 \pm 1.81(1-12)^{*}$ & $5.7 \pm 1.65(3-10)$ & $6.3 \pm 1.92(2-11)$ \\
Trial V & $9.6 \pm 2.53(4-15)$ & $11.1 \pm 2.23(5-15)$ & $11.5 \pm 2.23(7-15)$ \\
Total score & $39.3 \pm 9.84(15-72)$ & $44.8 \pm 8.57(21-63)$ & $47.4 \pm 9.97(30-68)$ \\
Delayed recall & $7.1 \pm 3.33(0-15)$ & $8.5 \pm 3.18(0-15)$ & $9.8 \pm 3.06(3-15)$ \\
Recognition & $11.6 \pm 2.70(4-15)$ & $12.7 \pm 2.16(5-15)$ & $13.5 \pm 1.69(9-15)$ \\
\hline *Mean score \pm SD (min-max). & & \\
\hline
\end{tabular}


Table 4 Correlation of age and WRAT-R with RAVLT scores and lead dose variables

\begin{tabular}{lcc}
\hline & Age & WRAT-R \\
\hline Age & - & \\
WRAT-R & $-0.25^{*}$ & - \\
Trial I & $-0.33^{*}$ & $0.29^{*}$ \\
Trial V & $-0.39^{*}$ & $0.40^{*}$ \\
Total score & $-0.44^{*}$ & $0.40^{*}$ \\
Delayed recall & $-0.37^{*}$ & $0.39^{*}$ \\
Recognition & $-0.26^{*}$ & $0.33^{*}$ \\
PbB & $0.18^{*}$ & -0.11 \\
TWA & $0.50^{*}$ & $-0.30^{*}$ \\
IBL & $0.71^{*}$ & $-0.32^{*}$ \\
\hline
\end{tabular}

*Pearson's $r$ significant at $\alpha<0.01$.

with delayed recall $(r=-0.13, \mathrm{p}<0.05)$ and recognition $(r=-0.17, \mathrm{p}<0.01)$.

When TWA was modelled on the trial $\mathrm{V}$ and delayed recall scores we found that it significantly contributed to the explanation of variance of both RAVLT variables after controlling for age and WRAT score $\left(\Delta R^{2}=1.4 \%\right.$, p $<0.03$; $\Delta R^{2}=1.4 \%, \mathrm{p}<0.03$, respectively). Likewise, when recognition and delayed recall scores were regressed on IBL after adjusting for the covariates, IBL significantly contributed to the explanation of variance of the former $\left(\Delta R^{2}=2.0 \%\right.$, $\mathrm{p}<0.02)$ and showed borderline significance in the case of the latter $\left(\Delta R^{2}=1.1 \%, \mathrm{p}=0.06\right)$.

In the two models using IBL we found evidence of possible multicollinearity between age and IBL (eigensystem condition number $=16.5$ in full model but variance inflation factors $<2.2$ for all three independent variables). Any possible effect on the variance of the beta coefficients in the model with recognition was not deemed to be of sufficient magnitude to preclude the inference of a significant contribution by IBL. As described in the statistical analyses section, the use of four age groups eliminated this concern for delayed recall. There was no evidence of interaction between the covariates or between either of the covariates and the exposure variables.

To examine the relation between lead exposure and different paradigms of verbal learning and memory we created three clinically relevant groups based on performance on trial V and recognition (table 6). Group I, the "no impairment" group had normal encoding, storage, and retrieval. ${ }^{33}$ Group II, the "retrieval difficulties" group was able to encode and store verbal information but could not retrieve that information from storage. ${ }^{19}$ Group III, the "generalised memory impairment" had abnormal encoding, retrieval, and storage but still showed the ability to learn new verbal information. ${ }^{19}$ Sixteen workers did not fulfil the case definition for one of these three memory groups and therefore were excluded from this analysis. Univariate analyses found no differences between these 16 workers and the 238 workers in the three memory groups on the demographic variables in table 1 ; however, these findings may be due to low power.

After adjusting for age and WRAT we used ANCOVA to compare the lead exposure of each of the three groups. There were no significant differences in $\mathrm{PbB}$ among any of the groups. While neither TWA nor IBL were significantly different between group I and group II, both TWA and IBL were significantly higher in group III compared to group I ( $p<0.05$ for both TWA and IBL comparisons).

Differences among the memory groups could not be explained by rate of forgetting, defined as the difference between trial $\mathrm{V}$ and delayed recall. All groups were similar; group III had a $15 \%$ word loss compared to $17 \%$ and $16 \%$ for group II and group I, respectively. Analyses of the types of errors (that is, repetitions, intrusions, and confabulations) found increasing problems across the memory groups. Details of the ANOVAs that compared groups II and III to group I are presented in table 7 . Repetitions were significantly higher for group I compared to groups II and III. One interpretation of increased repetitions without confabulations and intrusions is that it reflects increased effort to recall as many words as possible. Confabulations and intrusions, errors found with poor encoding and storage, were significantly more common in group III for recognition, and confabulations were more common in group III for delayed recall. As expected, group II had fewer errors than group III but significantly more confabulations only on recognition.

To explore serial position effects in recall (fig 1), we compared the mean number of words recalled from the first and third terciles of five words from the 15 word list: the scores on the two terciles represented primacy and recency performance. Adjusting for age and WRAT using ANCOVA, we found group I to perform significantly better in both serial order terciles when compared with groups II and III ( $\mathrm{p}<0.01$ for all comparisons). Group II had significantly better scores for the first tercile, showing better primacy list performance than group III $(\mathrm{p}<0.01)$. Overall, groups I and II showed better primacy than recency performance (group I remembered $74 \%$ of the first tercile words versus $69 \%$ of the third tercile words, and group II remembered 58\% versus $52 \%)$, while group III showed the opposite with slightly better recency than primacy performance (50\% of first tercile words versus $52 \%$ of third tercile words).

In fig 2, we examine primacy/recency performance within each trial. All three groups had better recency than primacy performance on trial I. Group I's primacy and recency performance improved across trials with primacy consistently greater than recency from trial II to trial V. Group II showed a similar pattern but the increase in primacy in trial $\mathrm{V}$ was at

\begin{tabular}{|c|c|c|c|c|c|c|c|c|}
\hline & Trial I & Trial V & Total score & $\begin{array}{l}\text { Delayed } \\
\text { recall }\end{array}$ & Recognition & PbB & TWA & IBL \\
\hline Trial I & - & & & & & & & \\
\hline Trial V & $0.33^{* *}$ & - & & & & & & \\
\hline Total score & $0.66^{* *}$ & $0.82^{* *}$ & - & & & & & \\
\hline Delayed recall & 1 $0.36^{* *}$ & $0.70^{* *}$ & $0.75^{\star *}$ & - & & & & \\
\hline Recognition & $0.25^{\star *}$ & $0.53^{* *}$ & $0.52^{\star *}$ & $0.63^{\star *}$ & - & & & \\
\hline $\mathrm{PbB}$ & -0.04 & -0.07 & -0.07 & -0.01 & -0.01 & - & & \\
\hline TWA & -0.03 & $-0.14^{*}$ & -0.10 & $-0.14^{*}$ & -0.11 & $-0.63^{\star *}$ & - & \\
\hline $\mathrm{IBL}$ & -0.09 & -0.11 & -0.11 & $-0.13^{*}$ & $-0.17^{\star *}$ & $-0.47^{* *}$ & $0.80^{* *}$ & - \\
\hline
\end{tabular}

*Pearson's $r$ significant at $\alpha<0.05$.

**Pearson's r significant at $\alpha<0.01$. 
Table 6 Verbal memory impairment as defined by the combined RAVLT trial $V$ and recognition scores

\begin{tabular}{llllllll}
\hline Memory pattern group & $\mathbf{n}$ & Trial V & Recognition & Delayed recall & PbB $(\mu \mathrm{g} / \mathrm{dll})$ & TWA $(\mu \mathrm{g} / \mathrm{dll})$ & IBL $(\mu \mathrm{g}-\mathrm{y} / \mathrm{dll})$ \\
\hline $\begin{array}{l}\text { Group I } \\
\text { "No impairment" }\end{array}$ & 125 & $12.6(1.41)$ & $13.9(1.08)$ & $10.5(2.34)$ & $26.6(9.24)$ & $35.4(12.94)$ & $589.5(431.44)$ \\
$\begin{array}{l}\text { Group II } \\
\text { "Retrieval difficulties" }\end{array}$ & 57 & $8.9(1.14)$ & $13.2(1.02)$ & $7.4(2.13)$ & $29.1(8.67)$ & $41.2(11.09)$ & $813.1(409.68)$ \\
$\begin{array}{l}\text { Group III } \\
\text { "Generalised memory impairment" }\end{array}$ & 56 & $8.0(1.54)$ & $9.2(1.90)$ & $6.8(2.88)$ & $28.5(8.16)$ & $44.1(9.88)$ & $935.1(368.36)$ \\
\hline
\end{tabular}

the expense of a drop in recency performance. Group III showed similar performance for recency and primacy on trials II to V.

\section{DISCUSSION}

On a test of verbal learning and memory, the RAVLT, inorganic lead exposure did not influence immediate memory span or verbal learning; however, difficulties with storage and retrieval of verbal information were significantly associated with chronic lead exposure. Storage and retrieval of information require the maintenance of learned information over time. Storage of verbal material is not related to the learning of new information. ${ }^{20}$ Retrieval is needed for free recall of a word list and may be impaired even while storage, as measured by recognition, remains intact. ${ }^{28}{ }^{36}$ Recognition uses cued recall and reflects information stored in memory, thereby eliminating the need of retrieval. ${ }^{28}{ }^{37}$ A semiquantitative dose-effect relation was found: group I with "no impairment" had a lower dose of chronic lead exposure than group II with "retrieval difficulties", that in turn had a lower dose of chronic lead compared with group III with "generalised memory difficulties".

Poor performance in the "generalised memory impairment" group could not be attributed simply to an inability to learn and retain new information, as recognition score was higher than delayed recall. Diminished recall with better recognition is similar to performance of individuals with impaired frontal lobe capacity. However, even individuals with impaired frontal lobe functions are still able to learn. ${ }^{19}$

In prior studies, digit span forward score, another measure of attention and verbal memory, was associated with $\mathrm{PbB}$ but at a concentration at the time of testing much higher than in this study. ${ }^{12}{ }^{14}$ Schwartz and colleagues ${ }^{38}$ and Stewart and colleagues $^{39}$ examined some components of the RAVLT (total score, delayed recall, and recognition) in workers exposed to organic and inorganic lead. Schwartz and colleagues ${ }^{38}$ reported poorer performance for total score and delayed recall with longer duration of exposure and cumulative combined exposure to organic and inorganic lead. Mean lifetime average blood lead $(24 \pm 9.4 \mu \mathrm{g} / \mathrm{dl})$ was low, suggesting that inorganic lead concentration in blood may not reflect the organolead taken up into the nervous system. Even though the toxicity of tetraethyl lead is due to its lead content, the fact that it is highly lipophilic allows it to be absorbed through the intact skin and selectively localised in the lipidrich nervous system. It is not clear whether the effects of exposure to organolead and inorganic lead can be directly compared to effects from only inorganic lead exposure.

Serial position in the word list can differentiate encoding mechanisms and those needed for efficiency of recall. The pattern of primacy/recency in the "no impairment" group, with recency stronger on trial I followed by a stronger primacy effect on subsequent trials and improvement across all trials for each segment, was identical to that reported in the study of normal aging by Mitrushina and colleagues. ${ }^{37}$ Stronger recency compatible with passive learning occurred in the "generalised memory impairment" group, with poorest recall from the beginning and the middle of the list. This pattern supports an encoding difficulty in the group that also had the highest measures of chronic lead exposure.

Acquisition of information occurs in the hippocampus while storage occurs in the cortex. Previous research using high resolution functional MRI of the medial temporal lobe during a memory task that required encoding and retrieval,

Table 7 Comparisons of errors among memory groups

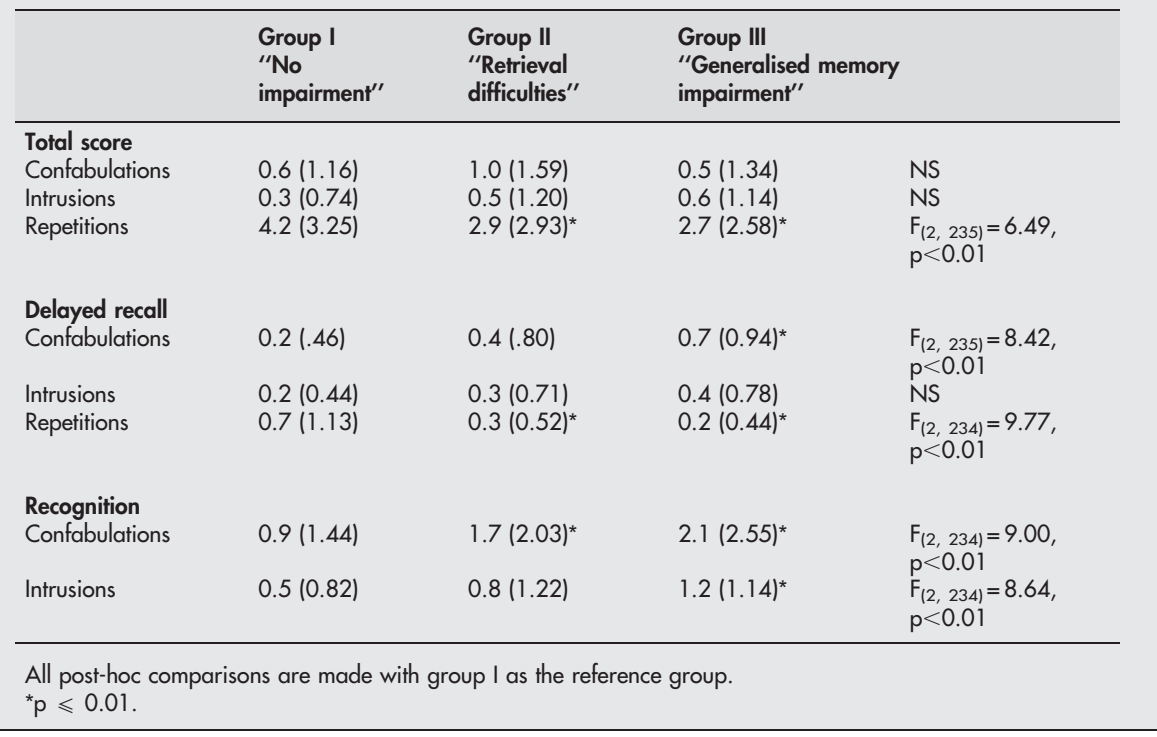




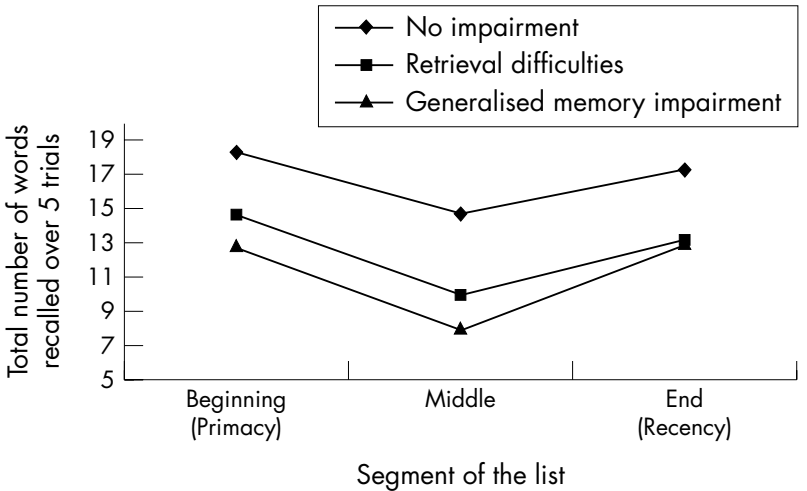

Group 1 = No impairment

Group 2 = Retrieval difficulties

Group 3 = Generalised memory impairment

Primacy comparisons

Group 1 and group $2-F_{(1,178)}=41.66, p<0.01$

Group 1 and group $3-F_{(1,177)}=64.66, p<0.01$

Group 2 and group $3-F_{(1,109)}=5.88, p<0.01$

Recency comparisons

Group 1 and group $2-F_{(1,178)}=35.67, p<0.01$

Group 1 and group $3-F_{(1,177)}=22.36, p<0.01$

Group 2 and group $3-F_{(1,109)}=0.31$, ns

Figure 1 Total words recalled by list segment.

found that different regions of the hippocampus were activated during encoding (anterior hippocampus) versus retrieval (posterior hippocampus). Activity also increased in the left prefrontal cortex and many surrounding brain regions during retrieval tasks as learning increased. ${ }^{40}$ This provides an anatomical basis for the memory groups. Since many areas of the brain are activated during retrieval, this may increase the risk of disruption by lead exposure.

Age and educational achievement contributed significantly to RAVLT performance. Normal aging in the absence of a known toxic exposure is associated with poorer performance on the RAVLT. ${ }^{36}$ In this population of lead smelter workers, the variance accounted for by age differed by the RAVLT variable ranging from $7 \%$ to $19 \%$. Studies of age related change on the RAVLT find preserved learning and recognition but faulty retrieval mechanisms. ${ }^{36}{ }^{374}{ }^{42}$ Retrieval is affected by both age related change and lead exposure, and therefore it is necessary to adjust for age before examining the contribution of lead exposure.

Many publications have reported the influence of educational achievement or verbal intelligence on the RAVLT performance. ${ }^{36434}$ This should not be surprising as verbal recall abilities can be enhanced through practice. WRAT, the measure of educational achievement, contributed variance to the RAVLT similar to age and ranged from $8 \%$ to $16 \%$. On functional MRI, individuals with superior verbal memory who used memory enhancing strategies showed greater activation of the right hippocampus, the medial parietal cortex, and the retrosplenial cortex.$^{45}$ Areas of the brain activated reflected the strategy used in recall, namely spatial recall.

This study was cross-sectional in design and therefore subject to the limitations of that design. The lead exposure terms of interest, IBL and TWA however, were based on data points collected at various times in the past, thus making causal inferences drawn from our results more likely to be valid. Likewise, selection bias was not likely to play a role in our findings as well over $80 \%$ of the smelter's eligible workers had volunteered to participate in the larger study, and all

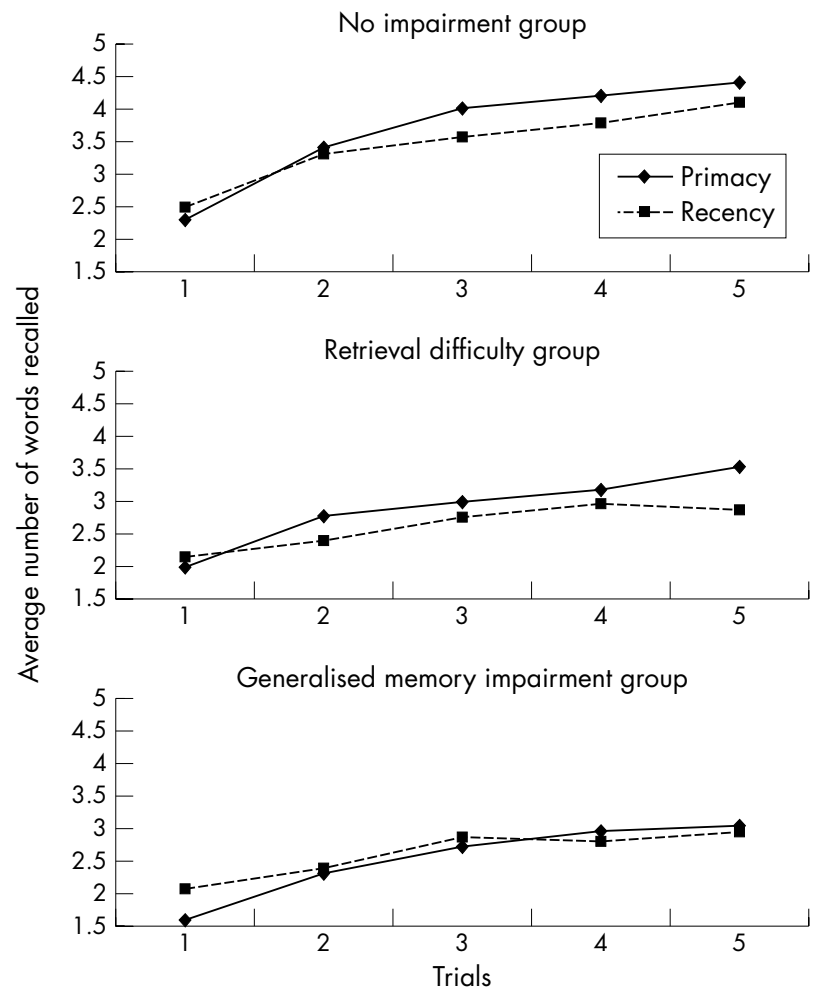

Figure 2 Average number of words recalled over trials by primacy and recency.

who met the selection criteria for the current investigation participated. The smelter was the major employer in the area and therefore had low turnover. Seniority was not necessarily associated with movement to less exposed jobs. Moreover, if a healthy worker effect existed it would have only served to lessen the association found between inorganic lead exposure and retention on a verbal memory task. The ability to generalise the results of this study could be biased by unmeasured geographic and historic variables unique to the population studied; for this reason these study results should be replicated in other locations.

While $\mathrm{PbB}$ was not associated with performance, chronic inorganic lead exposure resulted in poorer storage and retrieval of previously learned material on the RAVLT. This suggests that chronic lead exposure may alter the ability to organise material in long term memory, thereby interfering with retrieval efficiency. Chronic lead exposure differentially affects verbal learning/acquisition, encoding/storage, and retrieval of verbal information from the RAVLT. This study shows when inorganic lead exposure was high in the past; a low current blood lead level does not rule out a lead effect in a lead exposed individual with verbal memory impairment: chronic lead exposure must be considered.

\section{ACKNOWLEDGEMENTS}

The authors wish to thank Dr Daniel Malone for assistance with neuropsychological assessments.

\section{Authors' affiliations}

M L Bleecker, D P Ford, K N Lindgren, V M Hoese, K S Walsh, C G Vaughan, Center for Occupational and Environmental Neurology, Baltimore, Maryland, USA

Funding: Support received from New Brunswick Occupational Health and Safety Commission

Competing interests: none declared 


\section{REFERENCES}

1 Valciukas JA, Lillis R, Eisinger J, et al. Behavioral indicators of lead neurotoxicity: results of a clinical study. Int Arch Occup Environ Health 1978;41:217-36.

2 Baker E, Feldman RG, White RF, et al. Occupational lead neurotoxicity: a behavioral and electrophysiological evaluation. Study design and year one results. Br J Ind Med 1984;41:352-61.

3 Campara P, D'Andrea F, Micciolo R, et al. Psychological performance of workers with blood-lead concentration below the current threshold limit value. Int Arch Occup Environ Health 1984;53:233-46.

4 Mantere $\mathrm{P}$, Hanninen $\mathrm{H}$, Hernberg S, et al. A prospective follow-up study on psychological effects in workers exposed to low levels of lead. Scand J Work Environ Health 1984;10:725-7.

5 Stollery BT, Banks HA, Broadbent DE, et al. Cognitive functioning in lead workers. Br J Ind Med 1989;46:698-707.

6 Balbus-Kornfeld JM, Stewart W, Bolla Kl, et al. Cumulative exposure to inorganic lead and neurobehavioral test performance in adults: an epidemiological review. Occup Environ Med 1995;52:2-12.

7 Lindgren KN, Masten VL, Ford DP, et al. Relation of cumulative exposure to inorganic lead and neuropsychological test performance. Occup Environ Med 1996;53:472-7.

8 Bleecker ML, Lindgren KN, Ford DP. Differential contribution of current and cumulative indices of lead dose to neuropsychological performance by age. Neurology 1997:48:639-45.

9 Bleecker ML, Lindgren KN, Tiburzi MJ, et al. Curvilinear relationship between blood lead and reaction time: differential association with blood lead fractions derived from exogenous and endogenous sources. J Occup Environ Med 1997:39:426-31.

10 Haenninen H, Aitio A, Kovala T, et al. Occupational exposure to lead and neuropsychological dysfunction. Occup Environ Med 1998;55:202-9.

11 Hwang K-Y, Lee B-K, Bressler JP, et al. Protein kinase $C$ activity and the relations between blood lead and neurobehavioral function in lead workers. Environ Health Perspect 2002;1 10:133-8.

12 Grandjean P, Arnvig E, Beckmann J. Psychological dysfunction in leadexposed workers: Relation to biological parameters of exposure. Scand J Work Environ Health 1978;4:295-303.

13 Bleecker ML, Agnew J, Keogh JP, et al. Neurobehavioral evaluation in workers following a brief exposure to lead. In: Gilioli R, Cassitto MG, Foa V eds. Advances in the biosciences: neurobehavioral methods in occupational health. New York: Pergamon Press, 1983;46:255-69.

14 Pasternak G, Becker CE, Lash A, et al. Cross-sectional neurotoxicology study of lead-exposed cohort. Clin Toxicol 1989:27:37-51

15 Payton M, Riggs KM, Spiro A, et al. Relations of bone and blood lead to cognitive function: The VA Normative Aging Study. Neurotox Teratol 1998;20:19-27.

16 Johnson BL, Baker EL, El Batawi M, et al. Prevention of neurotoxic illness in working populations. New York: Wiley, 1997.

17 Anger WK, Cassitto MG, Liang Y-X, et al. Comparison of performance from three continents on the WHO-recommended neurobehavioral core test battery. Environ Res 1993;62:125-47.

18 Maj M, D'Elia L, Satz P, et al. Evaluation of two new neuropsychological tests designed to minimize cultural bias in the assessment of HIV-1 seropositive persons: a WHO study. Arch Clin Neuropsychol 1993;8:123-35.

19 Lezak MD. Neuropsychological assessment, 3rd edn. New York: Oxford University Press, 1995.

20 Query WT, Berger RA. AVLT memory scores as a function of age among general medical, neurologic and alcoholic patients. J Clin Psychol 1980;36:1009-12.

21 Mungas, D. Differential clinical sensitivity of specific parameters of the Rey Auditory-Verbal Learning Test. J Consult Clin Psychol 1983;51:848-55.

22 Rosenberg SJ, Ryan JJ, Prifitera A. Rey Auditory-Verbal Learning Test performance of patients with and without memory impairment. J Clin Psychol 1984;40:785-7.
23 Bigler E, Rosa L, Schultz F, et al. Rey-Auditory Verbal Learning and ReyOsterrieth Complex Figure Design performance in Alzheimer's disease and closed head injury. J Clin Psychol 1989:45:277-80.

24 Powell JB, Cripe LI, Dodrill CB. Assessment of brain impairment with the Rey Auditory Verbal Learning Test: a comparison with other neuropsychological measures. Arch Clin Neuropsychol 1991;6:241-9.

25 Erickson RC, Scott ML. Clinical memory testing: a review. Psychol Bull 1977:84:1130-49.

26 Ryan JJ, Rosenberg SJ, Mittenberg W. Factor analysis of the Rey AuditoryVerbal Learning test. Intern J Clin Neuropsychol 1984;6:239-41.

27 Ryan JJ, Paolo AM, Skrade M. Rey auditory verbal learning test performance of a federal corrections sample with acquired immunodeficiency syndrome. Int J Neurosci 1992;64:177-81.

28 Vakil E, Blachstein H. Rey auditory-verbal learning test: structure analysis. J Clin Psychol 1993:49:883-90

29 Defterman DK, Ellis NR. A factor analytic demonstration of two memory processes. Q J Exp Psychol 1970;22:484-93.

30 Wilson RS, Bacon LD, Fox JH, et al. Primary and secondary memory in dementia of the Alzheimer type. J Clin Neuropsychol 1983;5:337-44.

31 Tierney MC, Nores A, Snow WG, et al. Use of the Rey Auditory Verbal Learning Test in differentiating normal aging from Alzheimer's and Parkinson's dementia. Psychol Assess 1994;6:129-34.

32 Bleecker ML, Ford DP, Lindgren KN, et al. Association of chronic and current measures of lead exposure with different components of brainstem auditory evoked potentials. Neurotoxicology 2003;24:625-31.

33 Uchiyama CL, D'Elia LF, Dellinger AM, et al. Alternate forms of the auditoryverbal learning test: issues of test comparability, longitudinal reliability, and moderating demographic variables. Arch Clin Neruopsychol 1995; 10:113-45.

34 Bleecker ML, Lindgren KN, Ford DP, et al. The interaction of education and cumulative lead exposure on Mini-Mental State Examination. J Occup Environ Med 2002:44:574-8.

35 Jastak S, Wilkinson GS. The Wide Range Achievement Test-Revised: Administration manual. Wilmington: Jastak Associates, 1984.

36 Bleecker ML, Bolla-Wilson K, Agnew J, et al. Age-related sex differences in verbal memory. J Clin Psychol 1988:44:403-11.

37 Mitrushina M, Satz P, Chervinsky A, et al. Performance of four age groups of normal elderly on the Rey Auditory-Verbal Learning test. J Clin Psychol 1991:47:351-7.

38 Schwartz BS, Bolla Kl, Stewart W, et al. Decrements in neurobehavioral performance associated with mixed exposure to organic and inorganic lead. Am J Epidemiol 1993;137:1006-21

39 Stewart WF, Schwartz BS, Simons D, et al. Neurobehavioral function and tibial chelatable lead levels in 543 former organolead workers. Neurology 1999;52:1610-17.

40 Zeineh MM, Engel SA, Thompson PM, et al. Dynamics of the hippocampus during encoding and retrieval of face-name pairs. Science 2003:299:577-80.

41 Geffen G, Moar KJ, O'Hanlon AP, et al. Performance measures of 16- to 86year-old males and females on the auditory verbal learning test. Clin Neuropsychol 1990;4:45-63.

42 Bolla-Wilson KI, Bleecker ML. The influence of verbal intelligence, sex, age and education on the Rey Auditory Verbal Learning Test. Dev Neuropsychol 1986;2:203-11.

43 Wiens AN, McMinnes MR, Crossen JR. Rey auditory-verbal learning test: development of norms for healthy young adults. Clin Neuropsychol 1988;2:67-87.

44 Selnes OA, Jacobson L, Machado AM, et al. Normative data for a brief neuropsychological screening battery. Percept Mot Skills $1991 \cdot 73: 539-50$.

45 Maguire EA, Valentine ER, Wilding JM, et al. Routes to remembering: the brains behind superior memory. Nat Neurosci 2003;6(2):90-5. 